\title{
Laparoscopic Hernia Repair
}

\author{
Eva Deerenberg, Irene Mulder and Johan Lange \\ Erasmus University Medical Centre \\ The Netherlands
}

\section{Introduction}

A hernia is a protrusion of abdominal content (preperitoneal fat, omentum or abdominal organs) through an abdominal wall defect. Anatomically the most important features of a hernia are the hernial orifice and the hernia (peritoneal) sac, if present. The hernial orifice is represented by the primary defect in the aponeurotic layer of the abdomen, and the hernial sac by the bulging peritoneum. The neck of the hernial sac is located at the hernial orifice. As the French anatomist Henri Fruchaud (1894-1960) already stated, hernias of the abdominal wall occur in areas where aponeurosis and fascia are lacking the protective support of muscles (Fruchaud, 1953). Most of these weak areas are anatomically present in the abdominal wall congenitally, others may be acquired during life, for example by surgery. The uncovered weak aponeurotic areas are subject to elevated intra-abdominal pressures and give way if they deteriorate or represent anatomic varieties. The common sites of herniation of the abdominal wall are the groin, the umbilicus, the linea alba, the semilunar line of Spigel, the diaphragm and surgical incisions. In addition, more exceptionally obturator hernias and hernias of the triangle of Petit are also encountered. Hernias can broadly be classified into congenital and acquired types. Congenital hernias typically occur at the groin, although they may be observed at other locations such as the umbilicus or diaphragm.

Abdominal wall hernias represent a common issue in general surgical practice. The definitive treatment of all hernias, regardless of their origin or type, is surgical repair. It is suggested that a strategy of watchful waiting rather than surgery can be considered in patients with asymptomatic or minimally symptomatic inguinal and incisional hernia. The risks of delayed surgery are primarily related to the risks of incarceration and strangulation, which necessities emergency surgery. Elective surgical repair should be considered if the hernia is symptomatic, in case of an increased risk for incarceration or if the size of the hernia complicates dressing or activities of daily living. Hernias that are less likely to incarcerate include upper abdominal hernias, hernias with an abdominal wall defect larger than $7-8 \mathrm{~cm}$ and hernias less than $1 \mathrm{~cm}$ in diameter. The likelihood of incarceration decreases as the hernia defect increases in size since it is less likely that intestinal or visceral contents will become caught by a narrow neck of the hernia sac. In large incisional ('giant') hernias more skin problems (ischemia, necrosis and ulcerations) are observed and represent an indication for operation.

The surgical treatment of hernias is already performed since Hellenistic times when Celsus performed hernial sac extirpations. The founder of modern hernia surgery is Bassini from Padova (Italy), who performed the first anatomic hernia groin repair in 1887 (Bassini, 1887). 
The results of anatomical hernia repair were a large step forward, however recurrences kept frustrating surgeons since. Over de last decades it has become clear that prosthetic reinforcement by a non-resorbable synthetic polymer mesh is required for most hernia repairs. Abdominal wall hernias can be repaired with mesh reinforcement by open or laparoscopic approach. The first report of the use of a laparoscope in the repair of an abdominal wall hernia was made by Ger in 1982 (Ger, 1982). Bogojavalensky in 1989 was the first to report on the use of a prosthetic mesh during laparoscopic hernia repair (Bogojavalensky, 1989).

The objective of successful hernia repair is achieving a cost-effective repair with a low recurrence rate, minimal operative and acute and chronic postoperative pain with a rapid return to normal activities. Laparoscopic repair has the potential benefits of smaller wounds, with less wound infections and better cosmetic results, and the possibility to perform the procedure in the outpatient clinic. Patients are thought to experience less postoperative discomfort and a faster recovery time. Additional benefit, especially in incisional hernia surgery, is the possibility to diagnose and treat multiple hernias in one procedure. During laparoscopic repair a mesh is placed intraperitoneally which makes contact between the mesh and viscera inevitable. The contact with the viscera can lead to adhesion formation and associated complications like small bowel obstruction, enterocutaneous fistula, infertility and chronic pain. Other possible complications of the laparoscopic approach in general are bowel and bladder injuries, artery laceration, neuralgia and trocar site herniation. During laparoscopic hernia repair it is hardly ever possible to restore functional anatomy of the abdominal wall and manage skin redundancy or the hernia sac.

The risk of recurrence is determined by surgical-technical factors (i.e. mesh use, choice and placement), the experience of the surgeon, the occurrence of a wound infection and patient related factors. Literature shows that recurrence rates are low in experienced hands. Several co-morbidities have been identified that increase the risk of recurrence and wound infection following hernia repair: smoking, diabetes, coronary artery disease, chronic obstructive pulmonary disease (COPD), nutritional status, immunosuppression, chronic corticosteroid use, low serum albumin, obesity and advanced age. A prolonged operative time and the use of an absorbable synthetic mesh are also significant independent predictors of wound infection and associated recurrences.

\subsection{Mesh characteristics}

The first prosthetic mesh for hernia repair, introduced in 1900, was a hand-made silver wire filigrees. In the second half of the $20^{\text {th }}$ century nylon, (expanding) PTFE, polypropylene and polyester meshes were introduced. The current large diversity of synthetic polymer and biologic materials available for the reinforcement of hernia repair, without high level evidence for clinical use, complicates the selection of an appropriate prosthesis. The material must be reactive enough to stimulate fibroblast ingrowth, yet inert enough to minimize foreign body reaction, adhesion formation, allergic reaction and to avoid infection. The mesh must have enough strength to prevent early recurrence but enough flexibility to accommodate activity. The mesh should also have optimal laparoscopic handling characteristics. Until now the ideal mesh does not exist and the location of implantation (intra- or extraperitoneally) should be taken into account when choosing a mesh. When choosing a synthetic mesh for laparoscopic hernia repair it is important to consider all characteristics that generate the host response, like absorbability, pore size and weave. 
- Absorbability. Absorbable materials are less likely to become infected than nonabsorbable materials, and are less harmful to viscera. However the main disadvantage of absorbable meshes is that the resultant scar tissue weakens after the mesh is absorbed and the necessary long-term repair strength is not provided, in contrast with permanent non-absorbable meshes. Partial absorbable meshes are thought to decrease the amount of foreign material while maintaining mechanical strength, but data about the clinical (long-term) performances are not available yet. Total non-absorbable meshes can be more stiff and heavy, possibly causing discomfort for the patient.

- Pore size. Porosity of a mesh is the main determinant of tissue reaction. The space between fibrils influences cellular infiltration, risk of infection, and mesh density and flexibility. Meshes with large pores allow increased tissue ingrowth and are more flexible than meshes with small pores. In a microporous mesh the granulomas around individual fibrils can become confluent which leads to encapsulation of the mesh and makes the mesh inflexible. Microporous meshes are more at risk of becoming infected, as large immune cells cannot infiltrate to phagocytose bacteria. Due to the strong chronic host response, macroporous meshes show good incorporation, but are more likely to give rise to adhesions and erosions than microporous meshes when use intraabdominally. With increasing size of the pores, the chance of bulging of a macroporous mesh used for bridging increases.

- Weave. Multifilament meshes are soft, flexible and resistant to wrinkling. They result in strong integration in the host, but are more susceptible to infection. Monofilament meshes are less susceptible to infection, but have the disadvantage of causing significant adhesions when used intra-abdominally.

- Anti-bacterial of anti-adhesive treatment. Synthetic meshes with additional coatings (i.e. silver or antiseptics) to reduce the risk of infection or adhesions (i.e. cellulose or collagen layer) have been developed. The anti-adhesive layer functions as a barrier between the viscera and the mesh and reduces the risk of adhesion formation.

Biological meshes made of donor collagen (porcine, bovine or human) are suggested to be used especially in a contaminated or infected environment when closure is required. These new developed collagen meshes are thought to be replaced by the patients own collagen in time (remodelling), with an associated low adhesion formation and low infection risk.

They are less suitable for bridging; because due to gradual absorption, the risk of recurrence is high. Unfortunately collagen meshes cannot be introduced through a laparoscopy port yet and more research on outcome and recurrence rates should be done. Finally until now surgeons and hospitals are also reluctant as costs of biological meshes are very high compared to synthetic meshes.

\subsection{Mesh fixation}

During laparoscopic hernia repair the mesh can be placed intra- or extraperitoneally. For extraperitoneally placed meshes, commonly used during groin hernia repair, minimal to no fixation is required. This because when intraperitoneal pressure is evenly distributed over the large peritoneal surface from the inside the mesh is kept in place without need for fixation. However, some surgeons fixate the mesh in case of a direct inguinal hernia larger than $2 \mathrm{~cm}$. Fixation is then performed with tackers to the muscles and the periostal fascia of the pubic bone. Care must be taken to avoid the lateral space as all three inguinal nerves are located within. 
An intraperitoneally implanted mesh, commonly used in ventral hernia repair, can be fixated using different techniques. Proper fixation of the mesh is important to prevent recurrence, but no consensus about the ideal fixation method exists. The ideal fixation method would guarantee sufficient strength to withstand the pressures generated in the abdomen during coughing and straining. The first used fixation method was represented by stapling, using titanium staples with a penetration depth of 2 to $4.8 \mathrm{~mm}$. These staples could cause chronic pain by compression and twisting of tissue containing nerves. Currently, the most frequently used techniques involve fixation with transabdominal sutures and tackers; titanium helical coils with a maximal tissue penetration depth of $3.8 \mathrm{~mm}$. Fixation with tackers is fast and strong, but complications of adhesions to the tackers and nerve injury and intestinal lesions have been observed. Transabdominal sutures penetrate all layers of the abdominal wall, providing a significant stronger fixation than fixation with tackers only. The disadvantages of transabdominal sutures are the time consuming procedure and the increased risk of chronic postoperative pain by incorporating large bites of tissue.

When fixating a mesh it is important to use an appropriate amount of fixation points, avoiding loosening and incarceration of omentum or bowel loops. Transabdominal sutures should be placed no more than $5 \mathrm{~cm}$ apart. An overlap of $3 \mathrm{~cm}$ of the fascial defect is sufficient when transabdominal sutures are used. If no sutures are used the minimal overlap of the fascial defect should be 4 to $5 \mathrm{~cm}$. The tackers or staples should be placed every $2 \mathrm{~cm}$. Newly developed are absorbable tackers that absorb within one year. These absorbable tackers may lower the complication rate, but a tack is initially an invasive anchor that can result in nerve damage and postoperative pain. Completely non-invasive mesh fixation, such as with glue sealing, is gaining popularity in inguinal hernia repair, but use of glue in laparoscopic ventral hernia repair is not a common procedure yet. This fixation technique may be promising, but mesh dislocations, when positioned intraperitoneally, are reported.

\section{Hernias of the groin region}

The groin is the area of junction of the lower abdomen and the thigh at the myopectineal orifice of Fruchaud. The myopectineal orifice is bounded by the oblique and transversus abdominis muscles cranially, the iliopsoas muscles laterally, the rectus abdominis muscles medially and the pubic pecten caudally. This orifice is the weak spot through which neurovascular, muscular and testicular structures pass the abdominal wall during embryologic development. Protruding through the abdominal wall occurs at this point of the abdominal floor because no muscular covering reinforced by transversalis fascia is present.

The most common symptoms of a groin hernia are heaviness or a dull sense of discomfort in the groin that is most pronounced when the intra-abdominal pressure is raised, for example by straining or lifting. The pain is caused by the contents of the hernia pressing to the tight ring at the neck of the hernia sac. As the intra-abdominal pressure increases, the contents of the hernia are forced into the ring constricting them causing ischemia. Another cause of pain may be from stretching of the ilioinguinal or iliohypogastric nerves hard enter. In case of clinical suspicion of a groin hernia without palpable swelling herniography or MRI have the highest sensitivity and specificity. In daily practice ultrasonography with Valsalva manoeuvre is most often used.

The inguinal area is formed during embryologic development when the gubernaculum develops. This ligament exists between the ovary or testis and labioscrotal swelling and 
passes through the abdominal wall at the future inguinal canal. After twelve weeks of gestation the ventral peritoneal processus vaginalis follows the gubernaculum, equally piercing the abdominal wall. The processus vaginalis gives rise to the deep and superficial inguinal rings and pushes up the scrotal skin, the subcutaneous layers and the different investing layers of the spermatic cord. The spermatic cord consists of the internal spermatic fascia, cremasteric fascia and external spermatic fascia as continuations of transversalis fascia, internal and external oblique muscles, respectively. Thus, the cranial end of the inguinal canal is the internal or deep inguinal ring, which is a normal defect of the transversalis fascia. Its superior margin is represented by the transversus abdominis arch and the inferior margins are formed by aponeurotic fibers from the iliopubic tract, the inferior epigastric vessels, and the interfoveolar ligament of Hesselbach. The external or superficial inguinal ring is a triangular opening in the aponeurosis of the external oblique muscle. The superior and inferior crura, which form the margins of the ring, are held together and reinforced by intercrural fibers.

\subsection{Anatomy of the groin}

In the male within the 'triangle of doom' between the testicular vessels and vas deferens, the external iliac vessels are encountered. They are enveloped by lymphatic and fatty tissue. The deep circumflex iliac artery and vein originate from the external iliac vessels and run parallel to the iliopubic tract (ligament of Thomson), which is the thickened caudal margin of the transversalis fascia. This structure, which extends from the anterior superior iliac spine to the pubic tubercle, dorsally parallels the inguinal ligament. The latter is not visible from the posterior view.

The inferior epigastric artery and (two) veins are, especially in the laparoscopic extraperitoneal approach, the hallmark of safe exposure and entering of the proper preperitoneal space'. As the external iliac vessels are located within the endo-abdominal fascia, the inferior epigastric vessels pass to the dorsal aspect of the rectus abdominis muscles after perforation of the transversalis fascia, at the lateral boundaries of the rectus abdominis muscles. The frequently occurring accessory obturator artery and vein (corona mortis: 'circle of death'), connecting the obturator and inferior epigastric vessels, cross the superior pubic bone. They are at risk during dissection of the medial part of the pectineal ligament of Cooper, especially in femoral hernia surgery.

The genital branch of the genitofemoral nerve innervates the ventral genital skin and the cremaster muscle. After having accompanied the external iliac artery on the psoas muscle, it enters the inguinal canal through the deep inguinal ring, running dorsally to the round ligament of the uterus or the testicular vessels. Laterally to the deep inguinal ring, the lateral femoral cutaneous nerve crosses dorsally to the iliopubic tract, innervating the skin at the lateral side of the thigh. The femoral branch of the genitofemoral nerve and the lateral femoral cutaneous nerve are observed within the 'triangle of pain', also known as Kathouda's 'quadrant of doom'. The triangle is located between the gonadal vessels and iliopubic tract, at Bogros' space. Bogros' space is located between the transversalis fascia of ventral abdominal wall and the iliopsoas muscles, laterally to the inferior epigastric and external iliac vessels. In this area the application of staples for mesh prosthesis fixation is hazardous. The other nerves from the lumbar plexus (iliophypogastric, ilio-inguinal, obturator and femoral nerves) are only encountered if, inadvertently, dissection is performed between the transversus abdominis and iliopsoas muscles and the transversalis fascia. The nerves encountered in the triangle of pain from medial to lateral are the femoral branch of the genitofemoral nerve, the femoral nerve, 
the cutaneous branch of the femoral nerve and the lateral femoral cutaneous nerve. The anatomic landmarks and structures of importance are illustrated in the RISE (Rotterdam Institute of Surgical Endoscopy)-circle, figure 1 (Lange \& Kleinrensink, Surgical Anatomy of the Abdomen, Elsevier gezondheidszorg, 2002).

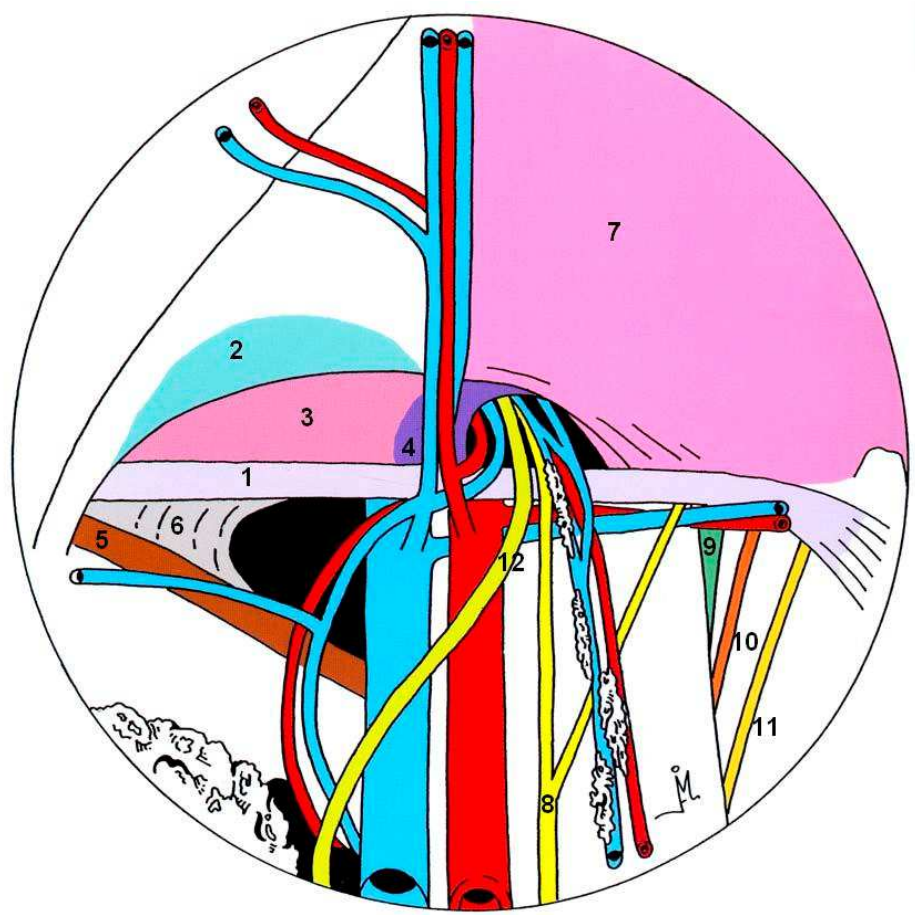

Ventromedial quadrant (direct hernia):

Base; iliopubic tract (of Thomson)(1)

Conjoint tendon(2)

Transeversalis fascia (caudal part of Hesselbach's triangle)(3)

Interfoveolar ligament (of Hesselbach)(4)

Branches of inferior epigastric vessels

Dorsomedial quadrant (femoral hernia at femoral canal/lacuna vasorum):

Pectineal ligament (of Cooper)(5)

Lacunar ligament (of Gimbernat)(6)

Bladder

Corona mortis

External iliac vein

Prevesical space (of Retzius)
Ventrolateral quadrant (indirect hernia):

Deep inguinal ring

Interfoveolar ligament (of Hesselbach)

Transversus abdominis muscle(7)

Fig. 1. RISE (Rotterdam Institute of Surgical Endoscopy)-circle. Anatomic landmarks and structures of importance in inguinal hernia repair (Lange \& Kleinrensink, Surgical Anatomy of the Abdomen, Elsevier gezondheidszorg, 2002). 
The contents of the inguinal canal differ between male and female. In the male the spermatic cord is surrounded by the cremasteric fascia and cremaster muscle. Within the cord, the spermatic vessels and vas deferens are surrounded by the internal spermatic fascia. The spermatic vessels are the internal spermatic (testicular) artery, the deferential artery and the external spermatic (cremasteric) artery and vein, accompanied by the venous pampniform plexus. Between the internal spermatic and cremasteric fascia, the genital branch of the genitofemoral nerve and the cremasteric vessels are observed. The external spermatic fascia envelops the cord caudally to the superficial inguinal ring. The contents of the inguinal canal in the female include the round ligament of the uterus, the artery of the round ligament of the uterus (Samson's artery), the genital branch of the genitofemoral nerve, the ilio-inguinal nerve and lymphatics.

\subsection{Different types of groin hernia}

Groin hernias are divided in inguinal and femoral hernias depending on their position in relation to the inguinal ligament. This structure is formed by the external abdominal oblique aponeurosis and the fascia lata of the thigh. It is located in between the anterior superior iliac spine and the pubic tubercle of the pubic bone.

- Inguinal hernias are located cranially to the inguinal ligament. The occurrence of inguinal hernias can be explained by the persistence of a processus vaginalis (indirect or lateral hernia), by a deficient fascia transversalis (direct or medial hernia) or by a combination of both.

- Femoral hernias occur through the opening located caudally to the ligament inguinal and medially to the femoral vein.

- Scrotal hernias are sometimes classified separately but are in fact large indirect inguinal hernias with a hernia sac reaching into the scrotum.

To distinguish an inguinal hernia from a femoral hernia clinically, or an indirect hernia from a direct hernia, is often impossible and is of little importance since the operation is nowadays the same.

\subsection{Inguinal hernia}

The inguinal hernia is one of the most frequently occurring hernias with an estimated 20 million hernias repair operations around the world. Estimated incidence rate in the UK is 13 per 10,000 population per year (Primatesta \& Goldacre, 1996). Indications for laparoscopic hernia repair are debatable. In case of a primary unilateral hernia an open mesh procedure is currently recommended by the European Hernia Society because of lower recurrence rate, costs and the possibility of local anaesthesia when compared with laparoscopic repair (Simons et al., 2009; Neumayer et al., 2004). From a socio-economic perspective, an endoscopic procedure is probably most cost-effective in patients participating in labour, especially in bilateral hernia. Furthermore chronic postoperative inguinal pain seems to be less generated by laparoscopic repair compared to conventional technique. All patients fit for general surgery without significant contraindications, including extreme age or significant cardiac, pulmonary or systemic illness, should be offered the option of a laparoscopic hernia repair (Simons et al., 2009).

\subsubsection{Classification}

To date, there is a lack of consensus among general surgeons and hernia specialists on classification systems for inguinal hernias. The traditional system classifies them into direct 
and indirect inguinal hernias. The persistence of a processus vaginalis is often described as a lateral or indirect hernia and a deficient transversalis fascia as a medial or direct hernia. In general clinical distinguishing is often difficult and irrelevant because treatment does not differ.

- Indirect inguinal hernias are the most common groin hernias in men and women. The hernia develops at the internal ring laterally to the inferior epigastric artery, in contrast to direct hernias which arise medially to the inferior epigastric vessels. Most indirect inguinal hernias are congenital, even though they may not become symptomatic until later in life (van Wessem et al., 2003). Indirect hernias develop more frequently on the right, because the right testicle descends later to the scrotum than the left.

- Direct inguinal hernias occur through the transversalis fascia at (the caudal part of) Hesselbach's triangle, formed by the inguinal ligament inferiorly, the inferior epigastric vessels laterally, and the rectus abdominis muscle medially. They occur as a result of a weakness of this part of the transversalis fascia, representing the floor of the inguinal canal. This weakness appears to be most often a congenitally diminished strength of collagen.

To be able to compare results most researchers choose to classify hernias by the classification of Nyhus (Nyhus, 1993):

- Type 1: Lateral/ indirect hernia with normal internal inguinal ring

- Type 2: Lateral/ indirect hernia with wide internal inguinal ring and normal

- Type 3a: $\quad$ Medial/ direct hernia

- Type 3b: Pantaloon- or combined hernia

- Type 4: Recurrent hernia

\subsubsection{Laparoscopic repair}

The two laparoscopic techniques that are currently most frequently performed are the transabdominal preperitoneal repair (TAPP) and the total extraperitoneal repair (TEP). Both TAPP and TEP use a mesh in the preperitoneal space as described by Stoppa to replace the visceral sac. These laparoscopic techniques were originally developed for repair of difficult and recurrent inguinal hernias, which were known to have high recurrence rates (Stoppa et al., 1984). Performance of a laparoscopic repair may be technically challenging if the patient has had prior prostatic surgery or lower abdominal radiotherapy. Currently no indications exist in which TAPP is preferred over TEP.

One of the major challenges in learning laparoscopic hernia repair is the relative unfamiliarity of most surgeons to the anterior abdominal wall anatomy from a posterior view. This unfamiliarity is mainly responsible for the steep learning curve, which is associated with an increased incidence of complications. Although peroperative complications are rare in laparoscopic repair, they occur more often early during the learning curve and are more critical. Reported complications include trocar injury to bowel and bladder, vascular injury to the inferior epigastric and femoral vessels, nerve entrapment, transection of vas deferens, and trocar site haemorrhage (Davis \& Arregui, 2003). After 250 laparoscopic repairs the recurrence rate is half of the rate of surgeons who have performed fewer repairs (Neumayer et al., 2004). If in future training would not be only incidental but more structurally organised with emphasis on anatomy including a defined proctorship it might be expected that learning curves will be much shorter. 


\subsubsection{TAPP}

The TAPP approach was first described by Arregui and colleagues in 1992 (Arregui et al., 1992). Performing a TAPP, firstly laparoscopic access into the peritoneal cavity is obtained. After identification of the inguinal hernia the peritoneum is incised several centimetres above the peritoneal defect. The peritoneum is incised from the edge of the median umbilical ligament toward the anterior superior iliac spine. Repair of bilateral hernias can be performed through two separate peritoneal incisions or one long transverse incision between the superior iliac spines. Subsequently the preperitoneal avascular space between the posterior and anterior fascia transversalis is dissected to provide visualization of the myopectineal orifice of Fruchaud and size of the abdominal wall defect. In case of an indirect hernia, the cord structures are isolated and dissected free from the surrounding tissues. Simultaneously, the indirect hernia sac is identified on the anterolateral side and adherent to the cord. The cord must be skeletonized with care to minimize trauma to the vas deferens and the spermatic vessels. If the sac is sufficiently small, it can be reduced into the peritoneal cavity. If the hernia sac is large it should be completely dissected and divided beyond the internal ring, and the subsequent peritoneal defect closed with an endoloop suture. The distal end of the transsected sac should be left open to avoid formation of a hydrocèle. When reducing a direct hernia sac, a "pseudosac" may be present, which consists of fascia transversalis that overlies and adheres to the peritoneum and invaginates into the preperitoneal space during the dissection. This layer must be separated from the true hernia sac in order for the peritoneum to be released back fully into the peritoneal cavity. Once the pseudosac is freed, it will typically retract anteriorly into the direct hernia defect.

A large piece of mesh, of at least $15 \times 10 \mathrm{~cm}$, is used to cover the myopectineal orifice, including the direct, indirect and femoral hernia spaces. It is important to dissect the preperitoneal space to prevent folding of the edge of the mesh within this space. In addition the mesh should be placed with a slight overlap of the midline to ensure adequate coverage of the entire posterior floor of the groin. The intraperitoneal pressure that is evenly distributed over the large surface of the mesh keeps it in place making fixation of the mesh controversial provided that elimination of fixation does not lead to an increased rate of recurrence. The use of tackers or sutures is associated with increased chronic inguinal pain, use of postoperative narcotic analgesia, hospital length of stay and the development of postoperative urinary retention (Koch et al., 2006; Taylor et al., 2008). Suitable structures for fixation are the contralateral pubic tubercle and the symphysis pubis, Cooper's ligament or the tissue just above it and the posterior rectus sheath and transversalis fascia at least $2 \mathrm{~cm}$ above the hernia defect. Fixation is never performed below the iliopubic tract laterally to the internal spermatic vessels, to minimize the chance of damage to the lateral cutaneous nerve of the thigh or the femoral branch of the genitofemoral nerve. Finally the mesh is covered by securing the peritoneal flap back to its original position. The peritoneum should be closed to eliminate the risk of formation of adhesions between the mesh and the intestine. The configuration of the mesh is also important. A slit in the mesh, although attractive in concept, can lead to constriction of the cord structures or allow herniation through the slit.

When using the TAPP technique, in addition to femoral hernias, especially sacless sliding fatty inguinal hernias may be overlooked because of intact peritoneum. Therefore, in cases of clinically diagnosed inguinal hernias, the preperitoneal space should be inspected intraoperatively to avoid unsatisfactory results (Hollinsky \& Sandberg, 2010). The main drawback of the TAPP procedure is that it requires entering of the peritoneal cavity with 
increased risk of injury to intra-abdominal organs. Further it requires subsequent incising the peritoneum with eventually peritoneal closure. The TEP was developed to avoid opening the peritoneal cavity with the associated risks.

\subsubsection{TEP}

The first to describe total extraperitoneal endoscopic repair of a inguinal hernias was Ferzli in 1992 (Ferzli et al., 1992). The procedure is initiated with a subumbilical incision followed by blunt dissection of the subcutaneous layer up to the anterior rectus sheath. The anterior rectus sheath is horizontally incised and with retractors the rectus abdominis muscle is searched and gently moved aside to bring the posterior rectus sheath in sight. The dissection of the preperitoneal space up to the symphysis is continued with a balloon. When using a balloon ('space maker') the thin fibrous layer of the posterior lamina of the fascia transversalis will rupture automatically to expose the 'proper preperitoneal space'. Subsequently a blunt tipped trocar is inserted into the preperitoneal space and a pneumoperitoneum is established. Additional trocars are inserted under direct vision. Further identification and repair of the inguinal hernia is identical to TAPP repair.

\subsubsection{Acute repair}

Acute repair of inguinal hernia is necessary in case of incarceration or strangulation. The cumulative probability of hernia getting strangulated after three months is $2.8 \%$ (Gallegos et al., 1991). The risks of postoperative complications following emergency surgery are high, and in elderly patients, mortality can be as high as 5\% (Nilsson et al., 2007; Primatesta \& Goldacre, 1996). Mostly open surgery is performed is case of incarceration to reduce the strangulated content, dissect the hernia sac and repair the abdominal wall defect. In 1993 Watson was the first to report acute laparoscopic reduction of the hernia with resection of the bowel (Watson et al., 1993). This reluctance may be attributable to the technical difficulties encountered in reducing the hernia sac and contents and the increased risk for iatrogenic injuries. The overall rate of complication, recurrence and hospital stay are very close to the rates documented in open repair for incarcerated hernias.

In case of a direct hernia, a releasing incision is made in the anteromedial aspect of the defect to avoid the inferior epigastric vessels. In indirect henias, the vessels are controlled, clipped and transected to facilitate the way for the releasing incision performed anteriorly in the deep (internal) ring at the 12 o'clock position toward the superficial (external) ring facilitating reduction of the incarcerated sac and its contents.

\subsection{Laparoscopic repair of inguinal hernia in children}

Laparoscopic repair of indirect hernia is nowadays one of the most frequently executed paediatric surgical procedures. Laparoscopic repair has the same advantages in children as in adults; less pain, faster recovery and better cosmesis. The overall incidence of inguinal hernias in childhood ranges from $0.8 \%$ to $4.4 \%$ (Bronsther et al., 1972), with predominantly indirect inguinal hernias. Incidence is higher in boys than in girls and in premature infants weighing less than 1000 grams with an incidence between 5 and 30\% (Harper et al., 1975; Rajput et al., 1992). Inguinal hernias in children are mostly the result of a patent processus vaginalis because of an arrest of embryologic development. The processus vaginalis closes between the $36^{\text {th }}$ and $40^{\text {th }}$ week of gestation, which explains the increased incidence of hernia in premature infants. Because the descend of the left testis takes place before the right 
testicle the closure of the processus vaginalis is equally asymmetric, which results in $60 \%$ of patent processus vaginalis occurrence on the right side. However only in $25-50 \%$ of patients with a patent processus vaginalis a clinically significant hernia will become apparent (Lau et al., 2007; van Veen et al., 2007). Diagnosis of inguinal hernia in children is often based on anamnestic information from the parents or physical examination showing a bulge in the groin with crying or coughing. For timing of elective surgery no evidence is available, but surgical repair is usually performed as soon as possible after diagnosis even if the hernia is asymptomatic. This because of fear of incarceration, although its exact risk has not been studied in paediatric watchful waiting studies. Additionally between 24 and $30 \%$ of patients present with incarcerated inguinal hernia (Moss \& Hatch, 1991; Puri et al., 1984). Manual reduction is successful in a majority of patients (Moss \& Hatch, 1991; Puri et al., 1984; Stringer et al., 1991). Many paediatric surgeons hospitalize children after successful manual reduction of incarcerated inguinal hernia and repair the hernia within 24-48 hours. The short delay allows the involved tissues to return to their normal texture before surgery. However some surgeons prefer immediate laparoscopy to inspect for vascular compromise of bowel, testicular or ovarian tissue with repair of the hernia.

The laparoscopic technique of inguinal hernia repair in children involves a high ligation of the indirect hernia sac without application of a mesh. First the spermatic cord is identified followed by dividing and tracing the sac in the inguinal channel without mobilization of the spermatic cord, with finally ligation of the hernia sac. In girls the surgeons must confirm before ligation that the hernia sac does not contain ovary, fallopian tube, or uterus. In addition to ligation and excision, plication of the floor of the inguinal canal may be necessary when the inguinal ring has been enlarged by repetitive herniation. In paediatric patients surgeons choose for primary repair because of the unknown effect of prosthesis material and because paediatric tissues have greater elasticity making primary repair more straightforward than in the adult population. A debate exists on exploration of the contralateral processus vaginalis during surgery to diagnose and treat asymptomatic contralateral hernia. The incidence of bilateral patent processus vaginalis has been described in literature between 5 and 12\% (Manoharan et al., 2005; Miltenburg et al., 1997; Tackett et al., 1999). In open surgery routine contralateral exploration is not recommended, because exploration increases the risk of testicular atrophy and infertility after cord injury. However in laparoscopic hernia repair, evaluation and treatment of the contralateral processus vaginalis is feasible without significant risk of injury to the vas and vessels. Additionally it decreases the need for later contralateral surgery. Femoral hernias in children are rare, occurring in less than 1\% of children with groin hernia. They often present as recurrent hernias after inguinal hernia repair, most likely because the surgeon was misled by the findings of a processus vaginalis at the initial surgery and missed the femoral hernia defect.

\subsection{Sportsmen hernia}

The term sportsmen hernia describes a condition characterized by chronic groin pain, without a demonstrable defect in the inguinal canal or abdominal wall, mostly observed in athletes. The pain flares with activity and results from chronic, repetitive trauma or stress to the musculotendinous portions of the groin. The exact pathophysiology is unclear and various theories have emerged in literature considering the presences of an occult hernia, a tear or microtears in the transversalis fascia or muscle strain. The theory that posterior weakness in the inguinal wall is the prime cause of groin pain in athletes is supported by the 
fact that reinforcement of the posterior wall often resolves the groin pain (Malycha \& Lovell, 1992; Paajanen et al., 2004; van Veen et al., 2007; Ziprin et al., 2008).

Sportmen hernia are found almost exclusively in men and only sporadically in women (Hackney, 1993; Moeller, 2007). For patients presenting with groin pain there are numerous other potential causes for groin pain, including hip articulation problems, taking in consideration the complex anatomy and biomechanics of the symphisis region. This makes the sportsmen hernia largely a clinical diagnosis of exclusion by physical examination and usage of radiological imaging. Sportsmen hernia can often be treated conservatively with rest, anti-inflammatiory medication and physiotherapy. However when pain persist after conservative treatment, laparoscopic mesh placement has shown to be a good option.

\subsection{Femoral hernia}

Femoral hernias account for 2 to $4 \%$ of groin hernias. Femoral hernia present more often in women and account for $23 \%$ of groin hernia operations in women, as compared with $1 \%$ in men (Dahlstrand et al., 2009). The reason for the higher incidence in women may relate to comparatively less bulky musculature at baseline and weakness of the pelvic floor muscles from previous childbirth. Additionally, the angle of the superior ramus of the pubic bone with the inguinal ligament is less acute in women, explaining for a wider femoral canal.

Femoral hernias frequently present acutely with signs of incarceration and require emergency surgery, with $40 \%$ emergency surgery in women and $28 \%$ in men. Subsequently bowel resection is required more often than in elective repair, $23 \%$ in emergency repair versus $0.6 \%$ in elective repair. Additionally, the risk for mortality is 5.4 times increased when compared to elective operations. This highlights the importance of repairing femoral hernias soon after presentation in an elective setting and suggests that there is no indication for watchful waiting in patients with femoral hernias. Strangulated Richter's type femoral hernias occur relatively frequent and carry a significant morbidity and mortality. The diagnosis of such strangulated femoral hernias is invariably delayed because they develop without intestinal obstruction and with minimal local manifestation until the entrapped knuckle of small bowel is gangrenous. A bruit over the femoral vein is an indication that the adjacent femoral hernia is incarcerated or strangulated because the hernia compresses the vein. Both open and laparoscopic approaches have been described for repair of femoral hernia. If a large volume of intra-abdominal contents has protruded into the hernia sac, or if there is bowel in the defect, laparoscopy is the operation of choice. Intra-abdominal contents are best removed by preperitoneal approach. Additionally during laparoscopy the viability of the bowel can be inspected.

\section{Hernias of the ventral abdominal wall}

Ventral hernias result from defects in the ventral abdominal wall and are typically classified by etiology and location. They can develop as a result of prior surgery (incisional and trocar site hernia) or at anatomical congenital weak locations (umbilical, epigastric and Spigelian hernia). The abdominal wall exists of five muscles (external oblique, internal oblique, transversus abdominis, rectus abdominis and pyramidal muscles) that protect the viscera. Herniation of the abdominal wall during activity is prevented by the transverse abdominal muscles. In adults the external oblique muscle is aponeurotic up to the level of the umbilicus. The caudal boundary of the posterior layer of the rectus sheath is the linea 
semicircularis, usually located $5 \mathrm{~cm}$ caudally to the umbilicus. Cranially to it, the medial aponeuroses of the three lateral muscles give rise to the anterior and posterior layers of the rectus sheath, enveloping the lateral border of the rectus sheath. Cranially to the umbilicus, the muscular part of the transversus abdominis muscle extends more medially than the muscular parts of the oblique muscles. Cranially to the umbilicus the abdominal cavity has an integral muscular cover, except for the linea alba in the midline. Caudally to the umbilicus, the medial borders of the external oblique and transversus abdominis muscles decline laterally, and the medial border of the internal oblique muscle medially. The transversus abdominis muscle is connected to the rectus sheath by its aponeurosis, the fascia of Spigel, which is cutaneously represented by the linea semilunaris (Lange \& Kleinrensink, Surgical Anatomy of the Abdomen, Elsevier gezondheidszorg, 2002).

\subsection{Technique of laparoscopic ventral hernia repair}

After establishing a pneumoperitoneum and introducing trocars, laparoscopic ventral hernia repair is started with lysis of intra-abdominal adhesions with caution to prevent bowel injury. After reduction of the hernial content, the hernia sac is commonly left in situ. In doing so seroma formation can occur. The fascial defect is measured and a piece of mesh able to cover the defect with an overlap of at least 3 to $5 \mathrm{~cm}$ is cut in shape. The intraabdominal pressure should be lowered to make the abdominal wall more natural shaped and to allow a flat placement of the mesh. The mesh is tension-free implanted and fixated with tackers (every $2 \mathrm{~cm}$ ) and possibly additional transabdominal sutures (at least every 5 $\mathrm{cm}$ ). Tackers can be placed in one row or a double row (double-crown technique). Drains are not typically used after laparoscopic hernia repair. Complications than can occur are related to laparoscopy (i.e. bowel injury and subsequent enterotomy), nerve injury by tackers or transabdominal sutures, adhesion formation to the mesh and fixation material, mesh infection and mesh dislocation.

\subsection{Incisional hernia}

An incisional hernia develops when the fascial tissue fails to heal at the incision site of a prior laparotomy. Incisional hernia is a common complication and represents about $80 \%$ of all ventral hernias. The highest incidence of incisional hernias is observed after midline laparotomy, the most common incision for abdominal surgery. In decreasing order of incidence, incisional hernias are diagnosed after upper midline incisions, lower midline incisions, transverse incisions and subcostal incisions. Incisional hernias are also described after paramedian, McBurney, Pfannenstiel and flank incisions.

Conditions that impair wound healing make patients susceptible to the development of an incisional hernia, such as wound infection, diabetes mellitus, obesity, immunosuppressive drugs, aneurysm of the abdominal aorta, connective tissue disorders and smoking. Approximately $15-20 \%$ of all patients will develop an incisional hernia after midline laparotomy (Hoer et al., 2002; Millbourn et al., 2009; Mudge \& Hughes, 1985). The incidence rises up to $35 \%$ in patients with an aneurysm of the abdominal aorta (Adye \& Luna, 1998; Bevis et al., 2010). Besides patient co-morbidities, technical failure contributes to the development of incisional hernia. After midline laparotomy the fascia should be closed with a non absorbable or slowly-absorbable continuous suture in a suture length to wound length ratio of 4:1 or more to lower the rate of incisional hernia (Hodgson et al., 2000; van 't Riet et al., 2002). 
Around $40 \%$ of incisional hernias are symptomatic and approximately 1 out of every 3 incisional hernias is repaired in an elective or emergency setting. In the United States, approximately 4 to 5 million laparotomies are performed annually, leading to 400,000 to 500,000 incisional hernias, of which approximately 200,000 repairs are performed (Burger et al., 2004).

\subsubsection{Classification}

Different classification systems for incisional hernias are available. The European Hernia Society developed a classification for incisional hernias which takes in account the location, size and possible recurrence of the incisional hernia (Muysoms et al., 2009). This classification allows comparison of publications and future studies on treatment and outcome of incisional hernia repair. Incisional hernias are classified by:

- Location:

- Midline: M1 (subxiphoidal), M2 (epigastric), M3 (umbilical), M4 (infraumbilical) and M5 (suprapubic)

- $\quad$ Lateral: L1 (subcostal), L2 (flank), L3 (iliac) and L4 (lumbar)

- Width: W1 (smaller than $4 \mathrm{~cm}), \mathrm{W} 2(4$ to $10 \mathrm{~cm}), \mathrm{W} 3(10 \mathrm{~cm}$ or more)

- Recurrence: yes or no

The Ventral Hernia Working Group (USA) developed a hernia grading system based on the characteristics of the patient and the wound (Ventral Hernia Working et al., 2010). Using this system a surgeon can assess the risk for surgical-site occurrences (infection, seroma, wound dehiscence, and the formation of enterocutaneous fistulae) for individual patients and thereby select the appropriate surgical technique, repair material, and overall clinical approach for the patient. The grading system with assessment of risk for surgical site occurrences:

- Grade 1, Low risk: patients without a history of wound infection and a low risk of complications

- Grade 2, Co-morbid: patients with one or more co-morbidities of smoking, obesity, diabetes mellitus, COPD, immunosuppression.

- Grade 3, Potentially contaminated: patients with a previous wound infection, stoma present or operation with violation of the gastrointestinal tract.

- $\quad$ Grade 4, Infected: patients with an infected mesh or septic dehiscence.

\subsubsection{Recurrence after laparoscopic repair}

Luijendijk (2000) and Burger (2004) stressed the importance of mesh reinforcement for incisional hernia repair, with long-term recurrence rates of $60 \%$ in the suture repair group and $32 \%$ in the mesh group. Recurrence rates following laparoscopic and open ventral hernia repair with prosthetic reinforcement are comparable (Bingener et al., 2007; Goodney et al., 2002; Sajid et al., 2009). Wound infection is one of the main contributors to the recurrence rate after laparoscopic ventral hernia repair, but surgical-technical failure is underestimated. Technical failure (i.e. inadequate mesh fixation, mesh overlap and lateral detachment) accounts for approximately $50 \%$ of the recurrences and infection for an additional 25\% (Awad et al., 2005). This explains the major decrease of recurrences in experienced hands, compared to non-experts. By laparoscopic ventral hernia repair the intraperitoneally placed mesh is pushed outward and held in place by the natural intraabdominal pressure. Another benefit of the laparoscopic approach is identifying small 
fascial defects, known as "Swiss cheese" defects, which may be missed during open repair. These small fascial defects are thought to be the major source of incisional hernia recurrence and therefore identification is important for a successful hernia repair.

\subsection{Trocar site heria}

Trocar site hernias (TSH) have an overall low incidence of less than $1 \%$ in adults. The incidence of TSH increases with the size of the used trocar. Almost all TSH develop from trocars of $10 \mathrm{~mm}$ or above. Most TSH are located at the umbilical port site, where the largest trocars are used and the fascia is expanded to remove surgical specimen. To prevent TSH the fascia of trocar sites of $10 \mathrm{~mm}$ or above should be sutured with a non-absorbable or slowly-absorbable suture, especially in the umbilical area. Co-morbidities as diabetes, smoking and obesity might be risk factors for TSH (Helgstrand et al., 2010). The use of a Veress Needle (instead of an open introduction technique) and a sharp trocar (compared to a conical shaped trocar) are associated with a higher incidence of TSH. In young children the reported incidence of TSH is higher than in adults (5\% vs $1 \%)$. Herniation of the small sized bowels through trocar ports of 3-5 $\mathrm{mm}$ is described, which shows the importance of closing all trocar port fascias in paediatric patients.

\subsection{Umbilical hernia}

A congenital umbilical hernia develops when the umbilical scar fails to heal at birth. The incidence of congenital umbilical hernia is $10-30 \%$, with a higher incidence in African American children than in Caucasian children. During the first 1.5 year of life most umbilical hernias close and at the age of 5 almost all children have complete closure of the umbilical ring. Repair should not be considered before an age of 3 years and only in children with large hernias that do not decrease in size or are symptomatic. In the rare case of incarceration, repair is necessary to avoid strangulation (Katz, 2001). Umbilical hernias in adults are an acquired defect in over $90 \%$ and are three times more frequently seen in women than in men. The development of an umbilical hernia is associated with obesity, abdominal distension, ascites and pregnancy. In females umbilical hernias are more frequent among multipara and are often easily reducible. Men often present with an incarcerated umbilical hernia, most often containing herniated omentum or preperitoneal fat. Laparoscopic umbilical hernia repair with an onlay patch is a safe and efficacious technique, and compared to open repair has the advantages of a lower rate of wound complications, reduced postoperative pain, shorter hospital stay and a diminished morbidity rate (Lau \& Patil, 2003; Toy et al., 1998). Hernia repair in the presence of ascites due to cirrhosis should be considered elective, since emergency repair has an associated morbidity of $70 \%$ and mortality of $5 \%$ (Telem et al., 2010). Even in patients with mild to moderate cirrhosis correction can be safely performed (Heniford et al., 2000).

\subsection{Epigastric hernia}

An epigastric hernia is a defect in the linea alba located between the xyphoid process and umbilicus. Epigastric hernias are comparable to umbilical hernias, but smaller in size, often less than $1 \mathrm{~cm}$ (Lang et al., 2002). Epigastric hernias are acquired defects with an incidence of $3-5 \%$, three times more frequent in men than in women and mostly diagnosed between $40-$ 60 years. Associated factors for the development of epigastric hernias are increased intraabdominal pressure and muscle or linea alba weakness. During laparoscopy an epigastric 
hernia can be difficult to visualize due to lack of peritoneal involvement through the hernia defect. Frequently epigastric hernias present incarcerated and in general only contain omentum or preperitoneal fat. Because of the small defect the hernia defect mostly need to be enlarged to reduce the hernial sac and its content.

\subsection{Spigelian hernia}

A Spigelian hernia is relatively rare, but more often diagnosed since the introduction of CTscan and laparoscopy. The Spigelian hernia occurs along the semilunar line at the level of the absence of the posterior rectus sheath (semicircular line, below the umbilicus). Almost all Spigelian hernias are interparietal due to the intact external oblique aponeurosis covering the hernia. A large Spigelian hernia is most often found laterally and inferior to its defect in the space directly posterior to the external oblique muscle.

The Spigelian hernia has different factors of etiology (Lange \& Kleinrensink, Surgical Anatomy of the Abdomen, Elsevier gezondheidszorg, 2002):

- Muscular gap between linea semilunaris and medial boundaries of oblique and transversus abdominis muscles, caudally to umbilicus,

- Maximal width of aponeurosis of transversus abdominis muscle at crossing of semicircular and semilunar lines.

- Parallelism of fibers of internal oblique and transversus abdominis muscles between arcuate line and Hesselbach's triangle.

- Blending of aponeuroses of internal oblique and transversus abdominis muscle into one separate structure, caudally to arcuate line.

Clinical diagnosis of a Spigelian hernia is challenging, but imaging with ultrasonography or CT-scan will confirm the presence of the hernia. Up to $20 \%$ of Spigelian hernias present incarcerated and therefore elective repair is indicated when diagnosed. The technique of laparoscopic repair is similar to other ventral hernia repairs. Compared to open repair, laparoscopic repair of Spigelian hernias is associated with a decreased morbidity, shorter hospital stay and low recurrence rate (Moreno-Egea et al., 2002).

\section{Diaphragmatic or hiatal hernia}

The diaphragm consists of striated muscle and has a collagenous central tendon, which is cranially blended with the pericardium. The esophageal hiatus is a $2-3 \mathrm{~cm}$ long muscular tunnel with a diameter of $3.5 \mathrm{~cm}$, located $2-3 \mathrm{~cm}$ to the left at the peripheral muscular part of the diaphragm. The right crus and dorsal median arcuate ligament encircle the esophagus. Through the esophageal hiatus, besides the esophagus, pass the vagus trunks, sensory phrenico-abdominal branch of left phrenic nerve to the pancreas and peritoneum, esophageal vessels and retro-esophageal fat.

The natural anti-reflux mechanism is complex with several synergistic elements. A crucial element in preventing reflux is the circular muscular lower esophageal sphincter (LES) of 3.5 $\mathrm{cm}$, extending from the distal esophagus down to the angle of His. The LES is autonomically controlled by vagal stimulation through intramural plexuses and enterohormones. Normally at least $1 \mathrm{~cm}$ of the LES is held intra-abdominally by the circular bilaminar phrenico-esophageal ligament. The ventral descending leaf connects the adventitia and muscular coat of the distal esophagus to the hiatus and is continuous with the lesser omentum at the right side of the esophagus. The supradiaphragmatic ascending leaf is 
elastic and permits movement during swallowing and breathing. The extrinsic component of the anti-reflux mechanism is the pinching action of the right crus of the diaphragm. The right crus narrows the hiatus and increases the angle between the ventrally bended distal esophagus and the cardia. The LES and crus normally supplement each other in preventing acid reflux during swallowing or acute increased intra-abdominal pressure (Lange \& Kleinrensink, Surgical Anatomy of the Abdomen, Elsevier gezondheidszorg, 2002).

A diaphragmatic or hiatal hernia occurs after enlargement of the hiatus and is a common disorder of the digestive tract. Cranial movement of the esophagus with protrusion of abdominal content (stomach in general) into the thoracic cavity can occur through the widened hiatus. This natural antireflux function is often disrupted by the presence of a hiatal hernia and is strongly associated with gastro-esophageal reflux disease (GERD). Hiatal hernias larger than $3 \mathrm{~cm}$ are a risk factor for erosive GERD and Barrett's esophagus.

\subsection{Classification}

Anatomically four different types of hiatal hernias can be recognised:

- Type 1: Sliding hernia. The gastroesophageal junction migrates into the thoracic cavity.

- Type 2: Paraesophageal hernia. Herniation of the gastric fundus anterior to a normally positioned gastroesophageal junction.

- $\quad$ Type 3: Mixed sliding and paraesophageal hernia.

- Type 4: Herniation of additional organs. The whole stomach and sometimes additional visceral organs (i.e. colon, omentum or spleen) migrate into the thoracic cavity. This can result in a stomach in upside-down position.

Up to $95 \%$ of all hiatal hernias can be classified as a type 1, sliding hernia. Type 3 and type 4 hiatal hernias tend to be large or giant hernias. Large or giant hernias are defined as at least $30 \%-50 \%$ of the stomach herniating into the thoracic cavity. Patients with hiatal hernia can experience symptoms of GERD, as epigastric pain, dysphagia, heartburn, but in more severe cases gastric hemorrhaging, vomiting and cardiopulmonary problems with dyspnea. Paraesophageal hernias account for less than $5 \%$ of all hiatal hernias but can have potentially life-threatening complications, such as obstruction, dilatation, necrosis with perforation or bleeding of the stomach.

\subsection{Laparoscopic repair}

Patients with sliding hernias and GERD should be considered for elective surgical repair. The objectives of hiatal hernia surgery for GERD are repair of the intrinsic component of the anti-reflux mechanism by bringing back LES into the hiatal tunnel and repair of the extrinsic component of the anti-reflux mechanism by narrowing the hiatus. Paraesophageal hernias (type 2, 3 and 4) should be repaired when symptomatic, due to the associated possible lifethreatening complications. The laparoscopic approach to hiatal hernia repair has the benefit of easy exposure of the hiatus area and a good vision into the mediastinum. To restore the intrinsic component of anti-reflux mechanism a laparoscopic fundoplication is performed. The laparoscopic Nissen fundoplication $\left(360^{\circ}\right.$ wrap) is the most frequently applied procedure. Other possible fundoplications are the posterior Toupet $\left(270^{\circ} \mathrm{wrap}\right)$ and anterior Dor $\left(180^{\circ}\right.$ wrap). The laparoscopic Nissen fundoplication is equally effective in patients with GERD or with paraesophageal hernia and is the preferred fundoplication procedure. The failure rate of a Nissen fundoplication for GERD is between 2-30\%, depending whether failure is defined as resumption of conservative treatment or failure requiring reoperation. 
The failure rate of a Nissen fundoplication for paraesophageal hernia is 7-33\%, depending whether failure is defined anatomically or symptomatically. Patient satisfaction after laparoscopic Nissen fundoplication with 5-year follow-up is 86-96\% (Lafullarde et al., 2001; Smith et al., 2005). Complications associated with laparoscopic hiatal hernia surgery include stenosis, pulmonary complications (pneumonia, pneumothorax, pulmonary edema) and gastrointestinal complications (bleeding, perforation, dysphagia).

\subsubsection{Laparoscopic fundoplication technique}

The patient should be positioned supine on a split leg table with arms out and in a steep reverse Trendelenburg position to help expose the hiatus. After establishing a pneumoperitoneum five trocars are inserted. A liver retractor is used to retract the left liver lobe and expose the anterior surface of the proximal stomach near the gastroesophageal junction. The hepatogastric omentum should be opened over the caudate lobe of the liver, just above the hepatic branch of the vagal nerve, exposing the right crus of the diaphragm. Caution should be taken for an aberrant left hepatic artery in this area, present in approximately $20 \%$ of patients. Over left, anteriorly the phrenoesophageal ligament can be divided to its apex on the right. The right and left crus are dissected from its base to the crural arch and the retroesophageal window is gently opened, protecting the posterior vagal nerve. A penrose drain can be used to retract the esophagus during further dissecting, until at least 2-3 cm of distal esophagus can be pulled below the diaphragm without tension. During this dissection caution should be taken not to injure the anterior and posterior vagal nerves, left or right pleura and aorta. The gastric fundus should be mobilized from $10-15 \mathrm{~cm}$ inferior to the angle of His, isolating and dividing the short gastric vessels, working back to the gastroesophageal junction. It is important to avoid excessive traction when dividing all posterior gastric arteries and other attachments, to prevent tearing of the short gastric arteries or splenic capsule. In some patients the proximal fundus and upper pole of the spleen are closely attached, making this part of the dissection quite difficult. The mobilized gastric fundus is brought through the retroesophageal window and around the distal esophagus anteriorly to ensure adequate mobilization. If the gastric fundus is released and exits the retroesophageal window, further mobilization is necessary. The fundoplication can be completed around a 50-60 French dilator. The internal diameter of the wrap should exceed the external diameter of the esophagus. Two or three non-absorbable sutures are placed with bites taking full thickness gastric fundus and partial thickness anterior esophageal wall, avoiding the anterior vagal nerve. When completed the wrap should be no greater than $2 \mathrm{~cm}$ in length and optimally a bit of distal esophagus should be visible distally to the wrap. Additional sutures from the wrap to the diaphragm can be placed. The crus can be closed using non-absorbable stitches.

\subsubsection{Paraesophageal hernia repair}

Laparoscopic repair of a paraesophageal hernia consists of reduction of the stomach and gastroesophageal junction into the abdominal cavity, complete excision of the peritoneal hernia sac from the mediastinum, and repair of the esophageal hiatus. Following a Nissen fundoplication, the crus should be closed using non-absorbable sutures. In case of a large hiatus, additional anterior or lateral crural stitches can be added. An additional anterior gastropexy can be performed in case of a very large or shortened esophagus. The anterior stomach wall and the antrum should be sutured to the abdominal wall. 
Laparoscopic repair of paraesophageal hernias is superior to open repair, with an associated decreased length of hospital stay, complication rate and recurrence rate (Draaisma et al., 2005). Long-term good functional results are observed in $75 \%$ and (symptomatic) recurrences in $15 \%$ after large paraesophageal hernia repair (Poncet et al., 2010). Postoperative complications associated with laparoscopic large paraesophageal hernia repair are intrathoracal wrap migration, relative stenosis of the cardia, gastric volvulus or strangulation, pneumothorax, pneumonia and dysphagia. A synthetic mesh can be used to reinforce the hiatal repair, but is still controversial. A mesh might be associated with a decreased recurrence rate, but may give rise to serious complications like prosthetic migration, esophageal perforation, dysphagia and mesh infection. Since the majority of paraesophageal hernias are mixed sliding and paraesophageal hernias, an insufficient LES with GERD-symptoms may remain after surgery and antireflux medication is still required.

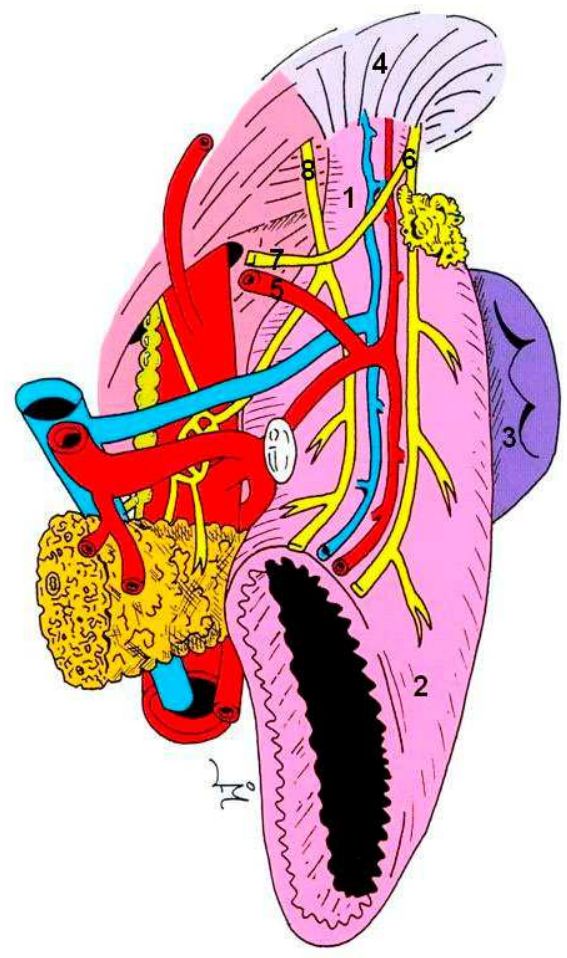

Esophagus (1)

Gastric fundus (2)

Splenic capsule (3)

Phrenico-esophageal ligament (4)

Abberant left hepatic artery (5)

Anterior vagus nerve (6)

Hepatic branch (7)

Posterior vagus nerve (8)

Fig. 2. Anatomic landmarks and structures of importance in hiatal hernia repair (Lange \& Kleinrensink, Surgical Anatomy of the Abdomen, Elsevier gezondheidszorg, 2002) 


\subsection{Treatment of recurrence}

The reported failure following laparoscopic Nissen fundoplication for GERD and paraesophageal hernia is between $2-33 \%$. Although failure of fundoplication is unusual when performed by an experienced surgeon, wrap herniation ('slipped Nissen') is the most common mechanism of failure. Other causes of failure are represented by disrupted fundoplication, slipped fundoplication, crural stenosis, too tight wrap, misplaced fundoplication or twisted fundoplication. In carefully selected patients who have recurrent or persistent symptoms (heartburn, dysphagia, chest pain, regurgitation, asthma, hoarsness or laryngitis) after laparoscopic or open fundoplication a laparoscopic redo fundoplication can be safely performed by an experienced surgeon. The overall conversion rate of redo laparoscopic fundoplication is $10 \%$. Complications occur in approximately $15 \%$, slightly increasing with multiple redos. After redo laparoscopic fundoplication $70 \%$ of patients is GERD-related symptom free (Smith et al., 2005).

\section{Parastomal hernia}

Occurrence of parastomal herniation is a common complication after stoma formation. The reported incidence of parastomal hernias varies from $28 \%$ in ileostomies to $56 \%$ in colostomies (Carne et al., 2003; LeBlanc et al., 2005; Rieger et al., 2004). A parastomal hernia is more likely to occur when the stoma emerges through the semilunar line rather than the rectus sheath. Although most hernias become present within two years after stoma construction, the risk of herniation extends up to 20 years.

\subsection{Classification}

Parastomal hernias can be classified in four types:

- Subcutaneous type: subcutaneous hernia sac

- Interstitial type: hernia sac within the aponeurotic layers of the abdomen

- Perstomal type: bowel prolapsing through a circumferential hernia sac enclosing the stoma

- Intrastomal: hernia sac between the intestinal wall and the everted intestinal layer

Symptoms patients may experience are pain, poor fitting of stoma-material resulting in leakage of stomal contents, obstruction, incarceration and cosmetic disfigurement. Fortunately, most parastomal hernias can be treated conservatively and surgical intervention is only indicated in $15 \%$ of patients with parastomal hernias (Hansson et al., 2003). Recurrence rates after surgical repair are reported up to $76 \%$, and can be explained by the underlying defect in wound healing and collagen metabolism in most patients.

\subsection{Laparoscopic repair}

Parastomal hernia repair with prosthetic mesh is recommended, since recurrence rates are unsatisfactory high after suture repair or relocation of the stoma. Complications that can arise with mesh placement for parastomal hernia are mesh-infection, fistula formation and adhesion formation. Laparoscopic repair is effective in correction of these hernias and has the advantages of improved vision and definition of the fascial edges of the hernia.

Laparoscopic techniques for repair of parastomal hernia with prosthetic mesh can be divided in 'keyhole techniques' and modified 'Sugarbaker techniques'. All involve introduction of trocars, extensive adhesiolysis, and identifying and measuring the fascial 
defect. A mesh should provide at least $5 \mathrm{~cm}$ of overlap of the fascial edges and should be secured with tacks or constructed with transfascial sutures.

Several different 'keyhole techniques' have been described, which have in common that a mesh is placed with a central hole or slit in the mesh to allow the bowel to pass through the mesh to the stoma site. One of the main drawbacks is shrinkage of the mesh that can result in obstruction or recurrent herniation by enlargement of the hole. In the modified Sugarbaker technique no hole is made in the mesh but the bowel to the stoma is lateralized and covered by the mesh (Berger \& Bientzle, 2007; Mancini et al., 2007; Sugarbaker, 1985). The mesh is secured to the abdominal wall at the margin of the mesh at $5 \mathrm{~cm}$ intervals. A second row of tackers is placed at the margin of the hernia defect with additional tackers at each side of the colon. Both techniques are promising, however long term results are not yet available. Perhaps prevention of development of parastomal hernia by placement of a lightweight sublay mesh is the key (Janes et al., 2004).

\section{References}

Adye, B., \& Luna, G. (1998). Incidence of abdominal wall hernia in aortic surgery. Am J Surg, 175(5), 400-402.

Arregui, M. E., Davis, C. J., Yucel, O., \& Nagan, R. F. (1992). Laparoscopic mesh repair of inguinal hernia using a preperitoneal approach: a preliminary report. Surg Laparosc Endosc, 2(1), 53-58.

Awad, Z. T., Puri, V., LeBlanc, K., Stoppa, R., Fitzgibbons, R. J., Jr., Iqbal, A., et al. (2005). Mechanisms of ventral hernia recurrence after mesh repair and a new proposed classification. J Am Coll Surg, 201(1), 132-140.

Bassini, E. (1887). Sulla cura radicale dell'ernia inguinale. Arch Soc Ital Chir, 4, 380.

Berger, D., \& Bientzle, M. (2007). Laparoscopic repair of parastomal hernias: a single surgeon's experience in 66 patients. Dis Colon Rectum, 50(10), 1668-1673.

Bevis, P. M., Windhaber, R. A., Lear, P. A., Poskitt, K. R., Earnshaw, J. J., \& Mitchell, D. C. (2010). Randomized clinical trial of mesh versus sutured wound closure after open abdominal aortic aneurysm surgery. Br J Surg, 97(10), 1497-1502.

Bingener, J., Buck, L., Richards, M., Michalek, J., Schwesinger, W., \& Sirinek, K. (2007). Long-term outcomes in laparoscopic vs open ventral hernia repair. Arch Surg, 142(6), 562-567.

Bogojavalensky, S. (1989). laparoscopic treatment of inguinal and femoral hernia (video presentation). In: Proceedings of the 18th Annual Meeting of the American Association of Gynecological Laparoscopists. Washington DC, USA.

Bronsther, B., Abrams, M. W., \& Elboim, C. (1972). Inguinal hernias in children--a study of 1,000 cases and a review of the literature. J Am Med Womens Assoc, 27(10), 522-525 passim.

Burger, J. W., Luijendijk, R. W., Hop, W. C., Halm, J. A., Verdaasdonk, E. G., \& Jeekel, J. (2004). Long-term follow-up of a randomized controlled trial of suture versus mesh repair of incisional hernia. Ann Surg, 240(4), 578-583; discussion 583-575.

Carne, P. W., Robertson, G. M., \& Frizelle, F. A. (2003). Parastomal hernia. Br J Surg, 90(7), 784-793.

Dahlstrand, U., Wollert, S., Nordin, P., Sandblom, G., \& Gunnarsson, U. (2009). Emergency femoral hernia repair: a study based on a national register. Ann Surg, 249(4), 672-676.

Davis, C. J., \& Arregui, M. E. (2003). Laparoscopic repair for groin hernias. Surg Clin North Am, 83(5), 1141-1161.

Draaisma, W. A., Gooszen, H. G., Tournoij, E., \& Broeders, I. A. (2005). Controversies in paraesophageal hernia repair: a review of literature. Surg Endosc, 19(10), 1300-1308. 
Ferzli, G. S., Massad, A., \& Albert, P. (1992). Extraperitoneal endoscopic inguinal hernia repair. J Laparoendosc Surg, 2(6), 281-286.

Fruchaud, H. (1953). [The effect of the upright position proper to man upon the anatomy of the inguinal region: surgical consequences; anatomic bases of surgical treatment of inguinal hernia]

Du retentissement de la position debout propre a l'homme sur l'anatomie de la region de l'aine: consequences chirurgicales; les bases anatomiques du traitement chirurgical des hernies de l'aine. Mem Acad Chir (Paris), 79(25-6), 652-661.

Gallegos, N. C., Dawson, J., Jarvis, M., \& Hobsley, M. (1991). Risk of strangulation in groin hernias. Br J Surg, 78(10), 1171-1173.

Ger, R. (1982). The management of certain abdominal herniae by intra-abdominal closure of the neck of the sac. Preliminary communication. Ann R Coll Surg Engl, 64(5), 342-344.

Goodney, P. P., Birkmeyer, C. M., \& Birkmeyer, J. D. (2002). Short-term outcomes of laparoscopic and open ventral hernia repair: a meta-analysis. Arch Surg, 137(10), 1161-1165.

Hackney, R. G. (1993). The sports hernia: a cause of chronic groin pain. Br J Sports Med, 27(1), 58-62.

Hansson, B. M., van Nieuwenhoven, E. J., \& Bleichrodt, R. P. (2003). Promising new technique in the repair of parastomal hernia. Surg Endosc, 17(11), 1789-1791.

Harper, R. G., Garcia, A., \& Sia, C. (1975). Inguinal hernia: a common problem of premature infants weighing 1,000 grams or less at birth. Pediatrics, 56(1), 112-115.

Helgstrand, F., Rosenberg, J., \& Bisgaard, T. (2010). Trocar site hernia after laparoscopic surgery: a qualitative systematic review. Hernia.

Heniford, B. T., Park, A., Ramshaw, B. J., \& Voeller, G. (2000). Laparoscopic ventral and incisional hernia repair in 407 patients. J Am Coll Surg, 190(6), 645-650.

Hodgson, N. C., Malthaner, R. A., \& Ostbye, T. (2000). The search for an ideal method of abdominal fascial closure: a meta-analysis. Ann Surg, 231(3), 436-442.

Hoer, J., Lawong, G., Klinge, U., \& Schumpelick, V. (2002). [Factors influencing the development of incisional hernia. A retrospective study of 2,983 laparotomy patients over a period of 10 years]

Einflussfaktoren der Narbenhernienentstehung. Retrospektive Untersuchung an 2.983 laparotomierten Patienten uber einen Zeitraum von 10 Jahren. Chirurg, 73(5), 474-480.

Hollinsky, C., \& Sandberg, S. (2010). Clinically diagnosed groin hernias without a peritoneal sac at laparoscopy--what to do? Am J Surg, 199(6), 730-735.

Janes, A., Cengiz, Y., \& Israelsson, L. A. (2004). Randomized clinical trial of the use of a prosthetic mesh to prevent parastomal hernia. Br J Surg, 91(3), 280-282.

Katz, D. A. (2001). Evaluation and management of inguinal and umbilical hernias. Pediatr Ann, 30(12), 729-735.

Koch, C. A., Greenlee, S. M., Larson, D. R., Harrington, J. R., \& Farley, D. R. (2006). Randomized prospective study of totally extraperitoneal inguinal hernia repair: fixation versus no fixation of mesh. JSLS, 10(4), 457-460.

Lafullarde, T., Watson, D. I., Jamieson, G. G., Myers, J. C., Game, P. A., \& Devitt, P. G. (2001). Laparoscopic Nissen fundoplication: five-year results and beyond. Arch Surg, 136(2), 180-184.

Lang, B., Lau, H., \& Lee, F. (2002). Epigastric hernia and its etiology. Hernia, 6(3), 148-150.

Lange \& Kleinrensink, Surgical Anatomy of the Abdomen, Elsevier gezondheidszorg, 2002.

Lau, H., \& Patil, N. G. (2003). Umbilical hernia in adults. Surg Endosc, 17(12), 2016-2020.

Lau, S. T., Lee, Y. H., \& Caty, M. G. (2007). Current management of hernias and hydroceles. Semin Pediatr Surg, 16(1), 50-57. 
LeBlanc, K. A., Bellanger, D. E., Whitaker, J. M., \& Hausmann, M. G. (2005). Laparoscopic parastomal hernia repair. Hernia, 9(2), 140-144.

Luijendijk, R. W., Hop, W. C., van den Tol, M. P., de Lange, D. C., Braaksma, M. M., JN, I. J., et al. (2000). A comparison of suture repair with mesh repair for incisional hernia. N Engl J Med, 343(6), 392-398.

Malycha, P., \& Lovell, G. (1992). Inguinal surgery in athletes with chronic groin pain: the 'sportsman's' hernia. Aust N Z J Surg, 62(2), 123-125.

Mancini, G. J., McClusky, D. A., 3rd, Khaitan, L., Goldenberg, E. A., Heniford, B. T., Novitsky, Y. W., et al. (2007). Laparoscopic parastomal hernia repair using a nonslit mesh technique. Surg Endosc, 21(9), 1487-1491.

Manoharan, S., Samarakkody, U., Kulkarni, M., Blakelock, R., \& Brown, S. (2005). Evidencebased change of practice in the management of unilateral inguinal hernia. J Pediatr Surg, 40(7), 1163-1166.

Millbourn, D., Cengiz, Y., \& Israelsson, L. A. (2009). Effect of stitch length on wound complications after closure of midline incisions: a randomized controlled trial. Arch Surg, 144(11), 1056-1059.

Miltenburg, D. M., Nuchtern, J. G., Jaksic, T., Kozinetz, C. A., \& Brandt, M. L. (1997). Metaanalysis of the risk of metachronous hernia in infants and children. Am J Surg, 174(6), 741-744.

Moeller, J. L. (2007). Sportsman's hernia. Curr Sports Med Rep, 6(2), 111-114.

Moreno-Egea, A., Carrasco, L., Girela, E., Martin, J. G., Aguayo, J. L., \& Canteras, M. (2002). Open vs laparoscopic repair of spigelian hernia: a prospective randomized trial. Arch Surg, 137(11), 1266-1268.

Moss, R. L., \& Hatch, E. I., Jr. (1991). Inguinal hernia repair in early infancy. Am J Surg, 161(5), 596-599.

Mudge, M., \& Hughes, L. E. (1985). Incisional hernia: a 10 year prospective study of incidence and attitudes. Br J Surg, 72(1), 70-71.

Muysoms, F. E., Miserez, M., Berrevoet, F., Campanelli, G., Champault, G. G., Chelala, E., et al. (2009). Classification of primary and incisional abdominal wall hernias. Hernia, 13(4), 407-414.

Neumayer, L., Giobbie-Hurder, A., Jonasson, O., Fitzgibbons, R., Jr., Dunlop, D., Gibbs, J., et al. (2004). Open mesh versus laparoscopic mesh repair of inguinal hernia. $N$ Engl J Med, 350(18), 1819-1827.

Nilsson, H., Stylianidis, G., Haapamaki, M., Nilsson, E., \& Nordin, P. (2007). Mortality after groin hernia surgery. Ann Surg, 245(4), 656-660.

Nyhus, L. M. (1993). Individualization of hernia repair: a new era. Surgery, 114(1), 1-2.

Paajanen, H., Syvahuoko, I., \& Airo, I. (2004). Totally extraperitoneal endoscopic (TEP) treatment of sportsman's hernia. Surg Laparosc Endosc Percutan Tech, 14(4), 215-218.

Poncet, G., Robert, M., Roman, S., \& Boulez, J. C. (2010). Laparoscopic repair of large hiatal hernia without prosthetic reinforcement: late results and relevance of anterior gastropexy. J Gastrointest Surg, 14(12), 1910-1916.

Primatesta, P., \& Goldacre, M. J. (1996). Inguinal hernia repair: incidence of elective and emergency surgery, readmission and mortality. Int J Epidemiol, 25(4), 835-839.

Puri, P., Guiney, E. J., \& O'Donnell, B. (1984). Inguinal hernia in infants: the fate of the testis following incarceration. J Pediatr Surg, 19(1), 44-46.

Rajput, A., Gauderer, M. W., \& Hack, M. (1992). Inguinal hernias in very low birth weight infants: incidence and timing of repair. J Pediatr Surg, 27(10), 1322-1324.

Rieger, N., Moore, J., Hewett, P., Lee, S., \& Stephens, J. (2004). Parastomal hernia repair. Colorectal Dis, 6(3), 203-205. 
Sajid, M. S., Bokhari, S. A., Mallick, A. S., Cheek, E., \& Baig, M. K. (2009). Laparoscopic versus open repair of incisional/ventral hernia: a meta-analysis. Am J Surg, 197(1), 64-72.

Simons, M. P., Aufenacker, T., Bay-Nielsen, M., Bouillot, J. L., Campanelli, G., Conze, J., et al. (2009). European Hernia Society guidelines on the treatment of inguinal hernia in adult patients. Hernia, 13(4), 343-403.

Smith, C. D., McClusky, D. A., Rajad, M. A., Lederman, A. B., \& Hunter, J. G. (2005). When fundoplication fails: redo? Ann Surg, 241(6), 861-869; discussion 869-871.

Stoppa, R. E., Rives, J. L., Warlaumont, C. R., Palot, J. P., Verhaeghe, P. J., \& Delattre, J. F. (1984). The use of Dacron in the repair of hernias of the groin. Surg Clin North Am, 64(2), 269-285.

Stringer, M. D., Higgins, M., Capps, S. N., \& Holmes, S. J. (1991). Irreducible inguinal hernia. Br J Surg, 78(4), 504-505.

Sugarbaker, P. H. (1985). Peritoneal approach to prosthetic mesh repair of paraostomy hernias. Ann Surg, 201(3), 344-346.

Tackett, L. D., Breuer, C. K., Luks, F. I., Caldamone, A. A., Breuer, J. G., DeLuca, F. G., et al. (1999). Incidence of contralateral inguinal hernia: a prospective analysis. J Pediatr Surg, 34(5), 684-687; discussion 687-688.

Taylor, C., Layani, L., Liew, V., Ghusn, M., Crampton, N., \& White, S. (2008). Laparoscopic inguinal hernia repair without mesh fixation, early results of a large randomised clinical trial. Surg Endosc, 22(3), 757-762.

Telem, D. A., Schiano, T., \& Divino, C. M. (2010). Complicated hernia presentation in patients with advanced cirrhosis and refractory ascites: management and outcome. Surgery, 148(3), 538-543.

Toy, F. K., Bailey, R. W., Carey, S., Chappuis, C. W., Gagner, M., Josephs, L. G., et al. (1998). Prospective, multicenter study of laparoscopic ventral hernioplasty. Preliminary results. Surg Endosc, 12(7), 955-959.

van 't Riet, M., Steyerberg, E. W., Nellensteyn, J., Bonjer, H. J., \& Jeekel, J. (2002). Metaanalysis of techniques for closure of midline abdominal incisions. Br J Surg, 89(11), 1350-1356.

van Veen, R. N., van Wessem, K. J., Halm, J. A., Simons, M. P., Plaisier, P. W., Jeekel, J., et al. (2007). Patent processus vaginalis in the adult as a risk factor for the occurrence of indirect inguinal hernia. Surg Endosc, 21(2), 202-205.

van Wessem, K. J., Simons, M. P., Plaisier, P. W., \& Lange, J. F. (2003). The etiology of indirect inguinal hernias: congenital and/or acquired? Hernia, 7(2), 76-79.

Ventral Hernia Working, G., Breuing, K., Butler, C. E., Ferzoco, S., Franz, M., Hultman, C. S., et al. (2010). Incisional ventral hernias: review of the literature and recommendations regarding the grading and technique of repair. Surgery, 148(3), 544-558.

Watson, S. D., Saye, W., \& Hollier, P. A. (1993). Combined laparoscopic incarcerated herniorrhaphy and small bowel resection. Surg Laparosc Endosc, 3(2), 106-108.

Ziprin, P., Prabhudesai, S. G., Abrahams, S., \& Chadwick, S. J. (2008). Transabdominal preperitoneal laparoscopic approach for the treatment of sportsman's hernia. $J$ Laparoendosc Adv Surg Tech A, 18(5), 669-672. 


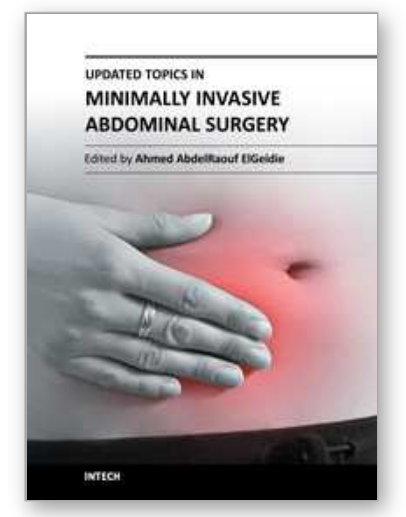

\author{
Updated Topics in Minimally Invasive Abdominal Surgery \\ Edited by Prof. Ahmed Elgeidie
}

ISBN 978-953-307-773-4

Hard cover, 246 pages

Publisher InTech

Published online 14, November, 2011

Published in print edition November, 2011

Updated topics in minimally invasive abdominal surgery provides surgeons interested in minimally invasive abdominal surgery with the most recent techniques and discussions in laparoscopic surgery. This book includes different topics covering a big variety of medical conditions with up-to-date information. It discusses many controversies in a clear and user-friendly manner. This book is made for young junior surgeons in training and also senior surgeons who need to know the most recent work in the field of laparoscopy. To make the material easily digestive, we provided the book with many figures and illustrations for different procedures and technical pearls.

\title{
How to reference
}

In order to correctly reference this scholarly work, feel free to copy and paste the following:

Eva Deerenberg, Irene Mulder and Johan Lange (2011). Laparoscopic Hernia Repair, Updated Topics in Minimally Invasive Abdominal Surgery, Prof. Ahmed Elgeidie (Ed.), ISBN: 978-953-307-773-4, InTech, Available from: http://www.intechopen.com/books/updated-topics-in-minimally-invasive-abdominalsurgery/laparoscopic-hernia-repair

\section{INTECH}

open science | open minds

\section{InTech Europe}

University Campus STeP Ri Slavka Krautzeka 83/A 51000 Rijeka, Croatia Phone: +385 (51) 770447

Fax: +385 (51) 686166 www.intechopen.com

\section{InTech China}

Unit 405, Office Block, Hotel Equatorial Shanghai No.65, Yan An Road (West), Shanghai, 200040, China 中国上海市延安西路65号上海国际贵都大饭店办公楼405单元 Phone: +86-21-62489820

Fax: $+86-21-62489821$ 
(C) 2011 The Author(s). Licensee IntechOpen. This is an open access article distributed under the terms of the Creative Commons Attribution 3.0 License, which permits unrestricted use, distribution, and reproduction in any medium, provided the original work is properly cited. 